\title{
O PAPEL DA INTERNACIONALIZAÇÃO ACADÊMICA NA PÓS-GRADUAÇÃO BRASILEIRA
}

\author{
THE ROLE OF ACADEMIC INTERNATIONALIZATION IN THE BRAZILIAN POST- \\ GRADUATION
}

DOI: http://dx.doi.org/10.23926//RPD.2526-2149.2018.v3.n2.p781-797.id279

\section{Stella Maris Wolff da Silva \\ Doutora em Educação em \\ Ciências (UFRGS). \\ Analista (CAPES). \\ wolffsms@gmail.com}

\section{Maria Rosa Chitolina \\ Doutora em Ciências - \\ Bioquímica (UFPR). \\ Professora da Universidade \\ Federal do Rio Grande do \\ Sul. \\ mariachitolina@gmail.com}

\section{Ivan Rocha Neto}

Doutor em Eletrônica pela

University of Kent, na

Inglaterra.

Professor colaborador na

Universidade Federal do Rio

Grande do Sul.

neto-ivan@hotmail.com
Resumo: O artigo pretende analisar a criação, institucionalização e expansão da pós-graduação brasileira a partir da promulgação da Lei de Diretrizes e Bases da Educação Nacional (LDB) e da reforma do ensino superior. Igualmente, discorrerá a respeito dos esforços que as Instituições de Ensino Superior (IES) têm envidado na busca de sua internacionalização acadêmica. Durante a pesquisa, foram levantadas publicações referentes à LDB, Reforma Universitária, e internacionalização da pós-graduação brasileira com as seguintes fases de seleção: 1- Trabalho aleatório na internet para a identificação de informações científicas da área da educação; 2Cruzamento de palavras-chave, por exemplo, reforma universitária; internacionalização da educação superior; internacionalização e globalização; 3- Identificação de periódicos científicos cujo conteúdo enunciasse a internacionalização da pós-graduação stricto sensu brasileira. A proposta da pesquisa, após a seleção das publicações, foi a de compilar e dar-lhes coesão no empenho de qualificar a pós-graduação diante da era atual.

Palavras-chave: Educação. Internacionalização. Pós-graduação brasileira.

\begin{abstract}
The article intends to analyze the creation, institutionalization and expansion of the Brazilian post-graduate course after the promulgation of the Law of Guidelines and Bases of National Education (LDB) and the reform of higher education. It will also discuss the efforts that the Higher Education Institutions (IES) have been making in the pursuit of their academic internationalization. During the research, publications related to LDB, University Reform and internationalization of the Brazilian post-graduate program were collected with the following selection phases: 1- Randomized work on the Internet to identify scientific information in the area of education; 2 - Crossing of keywords, for example: university reform; internationalization of higher education; internationalization and globalization; 3- Identification of scientific journals whose content enunciated the internationalization of the stricto sensu Brazilian post-graduation. The research proposal, after the selection of the publications, was to compile and give them cohesion in the effort to qualify the graduate before the current era. Keywords: Education. Internationalization. Brazilian Postgraduation.
\end{abstract}




\section{INTRODUÇÃO}

O presente trabalho é resultado do levantamento da literatura relativa à institucionalização, à expansão da pós-graduação brasileira e aos atuais esforços envidados pelas Instituições de Ensino Superior (IES) na busca de sua internacionalização acadêmica. A literatura levantada iniciou-se a partir de 1961, ano da promulgação da LDB, perpassando pela Reforma Universitária, em 1968, chegando aos dias atuais com o fenômeno da globalização. A partir dessa delimitação temporal, procedeu-se à análise da documentação referente ao referido período, observando-se, nas publicações científicas, palavras-chave tais como: reforma universitária; internacionalização da educação superior; e globalização, relacionando-as aos dias atuais. A pesquisa apresentada a seguir segue a ordem cronológica dos fatos relatados, LDB, Reforma Universitária e Globalização.

A primeira publicação da Lei de Diretrizes e Bases da Educação Nacional (LDB) foi debatida e elaborada no contexto de redemocratização do país, logo após a queda do Estado Novo (1937-1945), porém, sua promulgação deu-se em 1961, sob a Lei n 4.024/61, recebendo outras duas reformulações em 1971 e 1996.

A LDB define e regulariza o sistema de educação brasileiro, com base nos princípios presentes na Constituição Federal (CF) (BRASIL, 1988), sendo que a necessidade de sua formulação foi citada pela primeira vez na CF de 1934. Porém, só em 1946, com o fím da $2^{\mathrm{a}}$ Guerra Mundial, a qual será reportada nas linhas seguintes, na época em que o país tentava se reorganizar, é que se elaborou uma nova CF e nela havia menção clara da necessidade de ser elaborada uma lei específica e norteadora da educação nacional que viria a ser a LDB. Assim, cerca de trinta anos após sua primeira menção na CF de 34, a educação nacional ganhou sua primeira lei específica no dia 20 de dezembro de 1961, que, em sua essência, não trouxe alterações ao ensino tradicional, mas tornou o currículo flexível e alterável, dada a dimensão e diversidade do território nacional.

O golpe militar de 64 concedeu ao governo federal o controle das universidades públicas, sendo imposta a necessidade de que fosse realizada uma reforma para suprir os pedidos estudantis feitos à época. Assim, em 29 de novembro de 1968, foi publicada a Lei ${ }^{\circ}$ 5540/68, chamada de "Lei da Reforma Universitária", que estipulava normas de organização e de funcionamento do ensino superior, bem como sua articulação com o ensino médio. Dentre outras importantes deliberações, destacam-se: Estabelecimento da interdependência entre ensino, pesquisa e extensão; Instituição de regime integral e dedicação exclusiva dos 
docentes; Incentivo à produção científica e à titulação e a criação de oportunidades ao seu aperfeiçoamento acadêmico fora do Brasil.

Quanto à interdependência de ensino e pesquisa, a CF de 88, em seu artigo 207, dispôs que "as universidades [...] obedecerão ao princípio da interdependência entre ensino, pesquisa e extensão", ou seja, torna-se norma pétrea a interdependência dessas atividades universitárias e deixa claro que uma não pode existir sem a outra, e que nenhuma é acessória a outra, e sim seguimentos naturais: a produção científica, por exemplo, só pode cumprir seu papel social de difusora do conhecimento, por ser retroalimentada pelo ensino e pela extensão. E, ainda, o conhecimento científico aproxima a sociedade da universidade. Observamos tal tripé como um ciclo, em que a pesquisa cria e potencializa novos conhecimentos disseminados por meio do ensino e de se sua aplicação, a extensão, ou seja, as três atividades são interligadas e complementárias.

A reforma universitária esteve diretamente atrelada à educação superior, visando o desenvolvimento econômico em conformidade à idealização do governo militar de criar um modelo de ensino superior, de universidade e, consequentemente, de pós-graduação, dando clareza à sua finalidade. Consequentemente, a pesquisa e a pós-graduação brasileiras expandiram-se com a criação de cursos de pós-graduação stricto sensu, dada a política científica existente. Com ela, foram criados Centros Regionais de Pós-graduação que, mesmo vinculados ao sistema universitário, eram dotados de relativa autonomia. Uma das agências de fomento à pesquisa criada na década de cinquenta, o Conselho Nacional de Desenvolvimento Científico e Tecnológico $(\mathrm{CNPq})$, por exemplo, teve suas atribuições ampliadas, "incorporando à sua área de competência as ciências humanas, e inserindo-se esse órgão no complexo de mecanismos encarregados de exercer certos controles, a nível federal, sobre o sistema universitário de ensino e pesquisa e formação de cientistas" (MENDES, 2000, p. 28). Pode-se observar que, sob a égide militar, a educação superior foi sedimentada por uma política de desenvolvimento científico, época em que a pós-graduação foi estruturada, normatizada e institucionalizada, sendo criada outra importante agência de fomento, a Coordenação de Aperfeiçoamento de Pessoal de Nível Superior (CAPES).

A LDB foi reformulada, Lei $\mathrm{n}^{\circ}$ 5.692/1971, sob a mesma égide militar (1964-85) e não foram realizadas grandes alterações. Somente quando a democracia foi instalada no país, é que uma nova versão foi promulgada, em 20 de dezembro de 1996, recebendo o título de Lei Darcy Ribeiro sob o $n^{\circ}$ 9.394/96 (BRASIL, 1996). Esta nova versão produziu mudanças, ao procurar se tornar exequível em diferentes realidades da educação brasileira. E nas finalidades dadas à 
educação superior, foram destacados incentivos à pesquisa e à investigação científica, à divulgação de conhecimentos culturais, científicos e técnicos, e à promoção de extensão. E, além disso, foram previstos cursos sequenciais por campo de saber, de graduação, de pósgraduação, compreendendo cursos de mestrado e doutorado, de especialização e aperfeiçoamento. E quanto à gestão das universidades, foi garantida autonomia aos estabelecimentos públicos e particulares, e seu funcionamento garantido desde que 1/3 do corpo docente possuísse a titulação de mestrado, e que também 1/3 desse corpo trabalhasse em regime de dedicação integral.

Essa Lei condicionou o credenciamento, recredenciamento e o descredenciamento dos Programas de Pós-graduação (PPG) do Sistema Nacional de Pós-graduação (SNPG) ${ }^{1}$, mediante o resultado obtido na avaliação da pós-graduação stricto sensu (mestrados e doutorados), iniciada pela CAPES em 1976, que concede certificação à pós-graduação brasileira em nível internacional e faz com que esses PPG busquem, permanentemente, excelência em suas atividades de ensino, assim como sua internacionalização. Esse sistema de avaliação possui três fundamentos: 1) A avaliação é feita por pares, oriundos das diferentes áreas do conhecimento e reconhecidos por sua reputação intelectual; 2) Sua natureza é de meritocracia; e 3) Ela une reconhecimento e fomento, definindo políticas e estabelecendo critérios para o financiamento dos programas (CAPES, 2010).

Como instrumento balizador do SNPG, o resultado da avaliação influencia diversas decisões: Discentes baseiam-se nas notas dos PPG para escolherem seus futuros cursos; Agências de fomento nacionais e internacionais orientam suas políticas de fomento; e Estudos e indicadores produzidos pela avaliação podem induzir políticas governamentais de apoio e crescimento da pós-graduação, estabelecendo uma agenda que vise reduzir desigualdades nas regiões brasileiras e/ou no âmbito das áreas do conhecimento.

Desde seu estabelecimento, a avaliação dos PPG recebeu duas diferentes configurações. A primeira vigorou de 1976-1997, em que eram dados conceitos alfabéticos de "A" a "E". Os PPG de padrão internacional recebiam conceito A, e os que não poderiam permanecer no SNPG

1 O Sistema Nacional de Pós-graduação (SNPG) é constituído por meio de etapas: a primeira é a avaliação das propostas de cursos novos, em que, para a admissão de novos programas e cursos ao SNPG, a CAPES avalia a qualidade das propostas e se elas atendem ao padrão de qualidade requerido desse nível de formação e encaminha os resultados desse processo para, nos termos da legislação vigente, fundamentar a deliberação do CNE/MEC sobre o reconhecimento de tais cursos e sua incorporação ao SNPG. A Avaliação dos Programas de Pós-graduação compreende a realização do acompanhamento anual e da avaliação trienal do desempenho de todos os programas de pós-graduação que integram o SNPG. Os resultados desse processo, expressos pela atribuição de uma nota na escala de 1 a 7 , fundamentam a deliberação do CNE/MEC sobre quais cursos obterão a renovação de "reconhecimento", a vigorar no triênio subsequente, agora quadriênio (CAPES, 2010). 
recebiam conceituação "E”. A segunda configuração, que ainda é adotada, conceitua os PPG de "1" a "7". Os conceitos "6" e "7", topo do sistema, são concedidos aos PPG de padrão internacional. Os conceitos "4" e "5" indicam que os PPG têm desempenho bom e muito bom, e os de conceito " 3 " é indicado aos de médio desempenho. Por fím, conceitos "1" e "2" são conceitos insuficientes e provocam o descredenciamento do PPG no SNPG (NOBRE; FREITAS, 2017). Ainda em referência ao SNPG, podemos observar que é um Sistema sólido e em constante crescimento, conforme demonstração feita no Gráfico 1.

Gráfico 1 - Demonstrativo do crescimento do SNPG durante o período avaliativo de 2013 a 2017

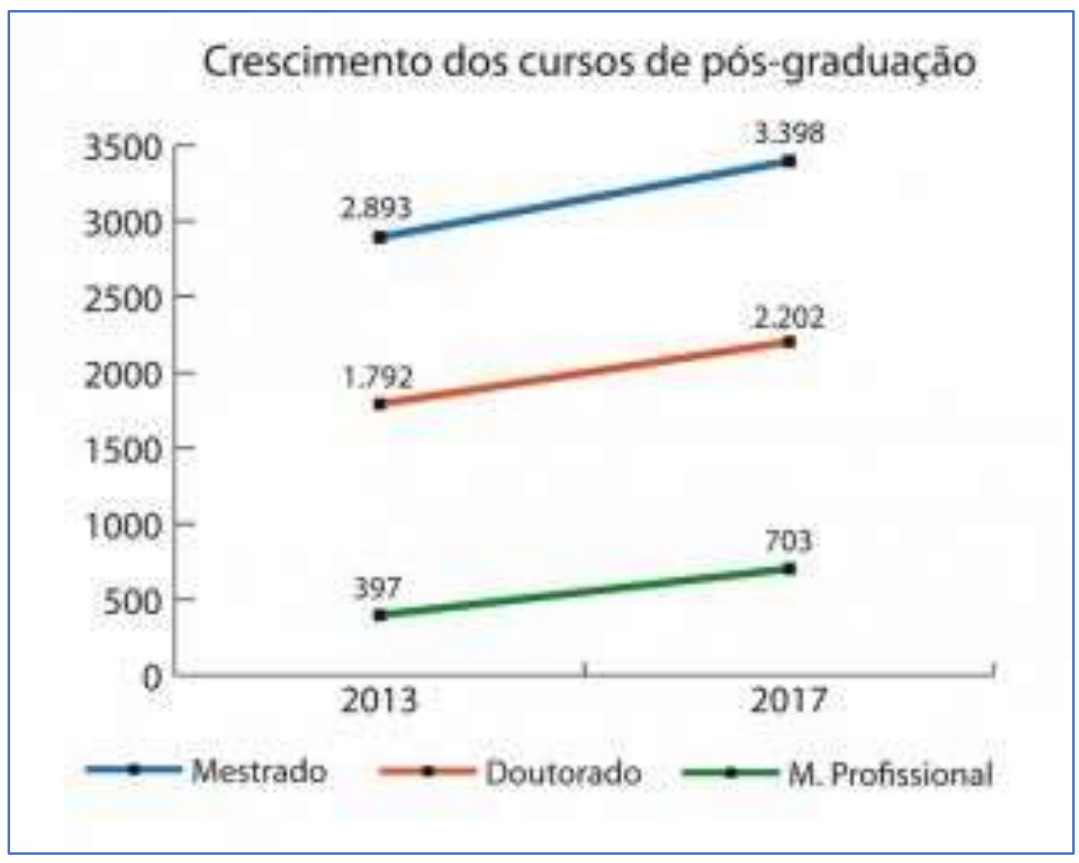

Fonte: CAPES, 2017.

Na avaliação realizada em 2017 com dados referentes ao quadriênio 2013 a 16, verificou-se o crescimento do SNPG em $25 \%$, a se dizer, em termos absolutos, que o número passou de 3.337, em 2013, para 4.175 programas, em 2016 (CAPES, 2017). Há que se dizer que, desse montante, 465 PPG (11\%) possuem desempenho equivalente a padrões internacionais de excelência, com notas 6 e 7, e que $18 \%$ alcançou a nota 5, nível 6 de excelência nacional com potencial para tornarem-se programas de excelência. 
Gráfico 2 - Distribuição de notas decorrente da última avaliação quadrienal/2017 realizada pela CAPES

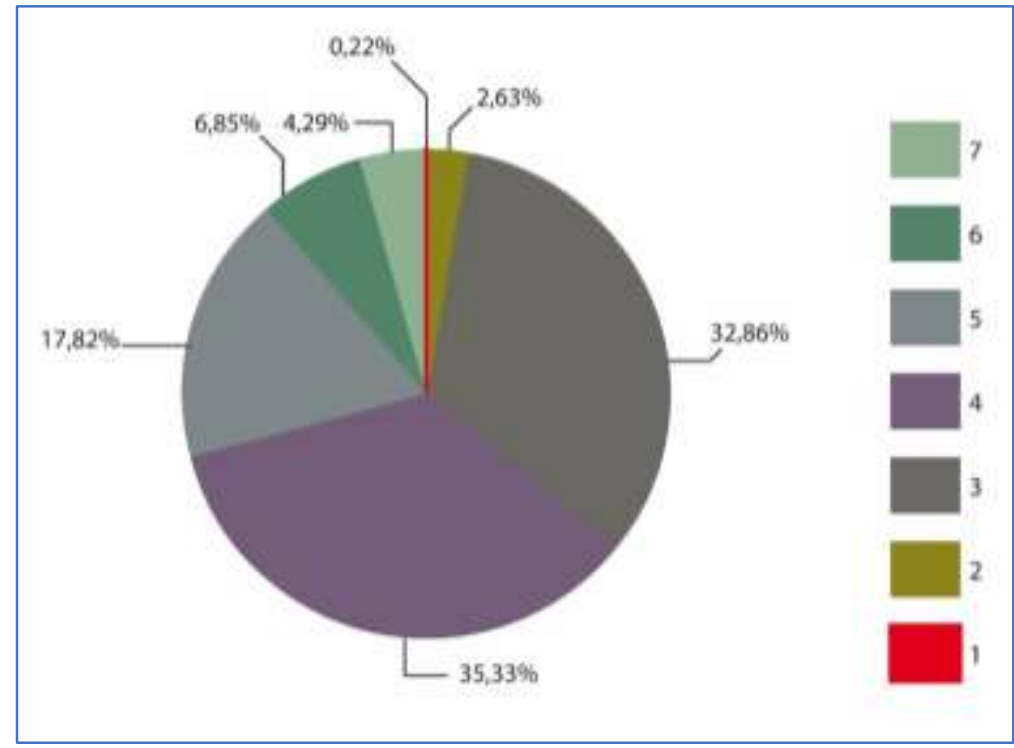

Fonte: CAPES, 2017.

Dentro de uma política de expansão e de fortalecimento da pós-graduação brasileira, e visando torná-la reconhecida internacionalmente por meio de publicações e de cooperação acadêmica de seus PPG de excelência, a CAPES instituiu, por meio da Portaria nº 220, de 3 de novembro de 2017, o Programa Institucional de Internacionalização de IES e de Institutos de Pesquisa do Brasil (PRINT), objetivando o fomento à construção, à implementação e à consolidação de estratégias à internacionalização das instituições de ensino, por meio da criação de redes de pesquisas internacionais, visando ao aprimoramento da produção, ao apoio acadêmico pós-graduado, à promoção da mobilidade de docentes e de discentes, ao incentivo à criação de um ambiente internacional nas IES, e integrar as ações de fomento da agência à internacionalização acadêmica. Esse programa visa à seleção de projetos institucionais de internacionalização dos PPG que possuam ao menos quatro PPG recomendados pela CAPES nas duas últimas avaliações, trienal de 2013 e quadrienal de 2017, dentre os quais deverá haver, ao menos, dois cursos de doutorado (CAPES, 2018).

Conforme afirma a Profa. Concepta McManus, atual Diretora de Cooperação Internacional (DRI) da CAPES,

\begin{abstract}
a internacionalização deve ser entendida como um meio e não como um fim em si mesmo. A internacionalização constitui-se na integração de uma dimensão internacional, intercultural ou global na finalidade, funções ou entrega de educação superior, com especial atenção à pós-graduação. Nesse contexto, CAPES-PRINT aporta contribuição fundamental para que o Brasil realize plenamente as suas potencialidades no que se refere à qualidade das pesquisas realizadas em âmbito nacional e à interface entre produção científica e inovação tecnológica com inserção internacional (CAPES, 2017).
\end{abstract}


Assim, na busca da internacionalização da pós-graduação stricto-sensu brasileira, certas ações foram destinadas ao seu fortalecimento, bem como ao reconhecimento internacional. Observamos sua institucionalização com a criação de duas importantes agências de fomento, CAPES e CNPq, e arrisca-se dizer que esse processo trouxe mudanças ao sistema de ensino universitário de forma intensa, e talvez maior que a reforma de 68.

\section{SinALIZAÇÕES DA GLOBALIZAÇÃO}

É sabido que à época da $2^{\text {a }}$ Guerra Mundial (II GM) havia divulgação radiofônica diária do chamado Repórter Esso ${ }^{2}$, criado pelos Estados Unidos da América (EUA). Essa divulgação era feita a 14 países, por meio de 59 estações radiofônicas, formando uma rede mundial de comunicação, mostrando ser uma forma de globalização da comunicação. Além dessa integração de informações, outros países, envolvidos ou não na II GM, uniram-se na tentativa de que uma nova atrocidade não fosse cometida, uniram-se com estratégias diplomáticas e comerciais e, dessa forma, surge a Organização das Nações Unidas ${ }^{3}$ (ONU), no ano de 1945, e com o avanço da tecnologia da informação, os países expandiram-se, cruzaram e ampliaram fronteiras, formando uma “Aldeia Global”, cujo intuito é o de unir diversidades e desigualdades, a despeito de igualá-las.

A sociedade global baseia-se na convicção de que a organização, o funcionamento e a mudança da vida social, em sentido amplo, compreendendo evidentemente a globalização, são ocasionados pela técnica e, neste caso, pela eletrônica.

Segundo Ianni (2002, p. 19), convém ressaltar a seguinte ideia:

A fábrica global instala-se além de toda e qualquer fronteira, articulando capital, tecnologia, força de trabalho, divisão do trabalho social e outras forças produtivas. Acompanhada pela publicidade, a mídia impressa e eletrônica, a indústria cultural, misturadas em jornais, revistas, livros, programas de radio, emissões de televisão,

2 Programa patrocinado pela Standard Oil Company ou ESSO - O nome é uma versão fonética das iniciais da Standard Oil (SO=ESSO) - era transmitido em 14 países do continente americano por 59 estações de rádio, constituindo-se na mais ampla rede radiofônica mundial. No Brasil, a síntese noticiosa, de cinco minutos, foi irradiada nos cinco principais centros de decisão política do País de 1941 a 1968: Rio de Janeiro, São Paulo, Belo Horizonte, Recife e Porto Alegre.

3 A Liga das Nações ou Sociedade das Nações foi uma organização internacional idealizada em 28 de abril de 1919, em Versalhes, França, onde as potências vencedoras da Primeira Guerra Mundial se reuniram para negociar um acordo de paz. Sua última reunião ocorreu em abril de 1946, dando lugar à Organização das Nações Unidas (ONU), ou simplesmente Nações Unidas, uma organização intergovernamental, visando à cooperação internacional, estabelecida em 24 de outubro de 1945, após o término da Segunda Guerra Mundial, com a intenção de impedir outro conflito como o que havia recentemente ocorrido. Na sua fundação, a ONU contava com 51 e, atualmente, conta com 193 estados-membros. Sua sede está localizada em Manhattan, Nova York, e possui extraterritorialidade, sendo financiada pelos países-membros e seus objetivos incluem manutenção da segurança e da paz mundial, promoção dos direitos humanos, auxílio no desenvolvimento econômico e no progresso social, proteção do meio ambiente, promoção da ajuda humanitária em casos de fome, desastres naturais e conflitos armados. 
videoclipes, fax, redes de computadores e outros meios de comunicação, informação e fabulação, dissolve fronteiras, agiliza os mercados, generaliza o consumismo. Provoca a desterritorialização e reterritorialização das coisas, gentes e ideias. Promove o redimensionamento de espaços e tempos.

Ao mesmo tempo, a chamada aldeia global pode ser encarada como contraditória e complexa por possuir, em seu bojo, sociedades, grupos, classes, tribos, nações, culturas, religiões e idiomas diferentes, em que o fenômeno da globalização é um processo sólido e irreversível, e funciona como amálgama que tem tornado o planeta uma aldeia: "Para todos, porém 'globalização' é o destino irreversível do mundo, um processo irreversível, é também um processo que nos afeta a todos na mesma medida e da mesma maneira” (BAUMAN, 1999, p. 7). Desse modo, por ser um fenômeno que não pode ser revertido, as nações procuram fazer adaptações em variadas esferas na busca de um entendimento comum, conforme Goergen (2013, p. 248) pontua:

Seja como for, entre críticas e aplausos, a globalização, internacionalização ou transnacionalização, como às vezes se prefere, é um fenômeno incontornável de um novo momento cultural e econômico envolvendo todas as pessoas, inclusive as de lugares muito remotos, e todas as áreas da atividade humana.

Dentro dessa irreversibilidade, quanto ao ensino, reportamo-nos ao processo de internacionalização da educação europeia quando, em 1998, encabeçada por Alemanha, França, Itália e Reino Unido, foi assinada a Declaração de Sorbonne em Paris, com o intuito de se criar um Espaço Europeu de Ensino Superior (EEES) ${ }^{4}$, com o propósito de criar uma área europeia de ensino superior, aumentar a empregabilidade e mobilidade dos cidadãos europeus, e dar competitividade internacional ao ensino superior europeu (VEIGA, 2003).

Para Antunes (2006), o Processo de Bolonha, que culminou com sua Declaração, mostrou ser uma forma inovadora de fazer política educacional, ao ampliar a atratividade educacional dos países europeus envolvidos, pois, ao reduzir burocracias, concedeu um novo perfil à educação superior. Dias Sobrinho $(2005$, p. 4), por sua vez, sinaliza que a Declaração de Bolonha procura adaptar os currículos às demandas e às características de um novo mercado de trabalho, impulsionando a mobilidade de estudantes, professores e funcionários e, não menos importante, tornando a educação superior atraente no mercado da globalização, conforme também sinaliza Lombas (2013, p. 53):

Neste sentido, ressalta-se a expansão dos mercados internacionais do ensino superior e o aumento de parcerias e alianças institucionais com congêneres e não congêneres

\footnotetext{
O objetivo principal do Processo de Bolonha, iniciado em 1999, foi o de criar o Espaço Europeu de Ensino Superior. Assim, entre 1999 e 2010, todos os países aderentes ao tratado de Bolonha se esforçaram por sua criação, o que viria a tornar-se realidade com a Declaração Budapeste-Viena, no dia 12 de março de 2010.
} 
estrangeiros focalizadas nas funções de ensino e pesquisa, que, por conseguinte, passam a mobilizar um maior contingente de estudantes e pesquisadores estrangeiros.

Por não haver consenso quanto à distinção entre o fenômeno da globalização e o processo de internacionalização na educação, torna-se difícil defini-los. O que se sabe é que um processo influencia outro, conforme referenciado em Knight e Wit (1997, p. 6), "a internacionalização está mudando o mundo da educação e a globalização está mudando o mundo da internacionalização". Ainda dentro desse contexto, Altbach (2004, p. 3) afirma que internacionalização se confunde com globalização, mas que esta pode ser "definida como o resultado inevitável das amplas tendências econômicas, tecnológicas e científicas que diretamente afetam a educação superior”. Podemos corroborar em Knight e Wit (1997, p. 6) que a globalização é um fenômeno em que há "fluxo de tecnologia, economia, conhecimento, pessoas, valores, ideias, através das fronteiras. E que ela afeta cada país de modo diferente devido à história, tradições, cultura e prioridades da nação", conceito este reafirmado em Altbach e Knight (2007) nos seguintes termos:

[...] ela se relaciona com o contexto de tendências econômicas e acadêmicas do século XXI e que, no campo da educação superior, a internacionalização é o conjunto de políticas e práticas desenvolvidas pelos sistemas acadêmicos, pelas instituições e pelos indivíduos para fazer frente ao ambiente acadêmico global.

Miura (2006) indica razões para que as IES busquem sua internacionalização, a saber:

- Razões políticas, busca pela paz e entendimento mútuo;

- Razões econômicas, preocupação com a competitividade e crescimento econômico;

- Razões socioculturais, expansão de valores morais e nacionais; e

- Razões acadêmicas, qualificação das pessoas para o mercado de trabalho, reputação da IES, qualidade do ensino, pesquisa e serviços, exposição cultural decorrente da mobilidade de estudantes e professores.

Para a pós-graduação, a internacionalização é um meio de se conquistar a excelência acadêmica, acesso às publicações internacionais, melhores condições para divulgação de pesquisas em diferentes e melhores periódicos. A CAPES é uma das agências de fomento a dar importância à internacionalização por ser a responsável pela avaliação da pós-graduação stricto sensu brasileira e por fomentar a concessão de bolsas de ensino, e ainda por se empenhar para que as IES atinjam excelência e consequente projeção internacional (CAPES, 2018).

Diante do exposto em Knight (2004), preconiza-se que a internacionalização acadêmica adquire uma nova razão de ser e que deve ser somada a razões política, econômica, sociocultural e acadêmica. Desse modo, a quinta razão vem ser a reputação internacional, branding, e que possui finalidades acadêmicas, econômicas, sociais e/ou políticas. E essa internacionalização 
lhes concederia visibilidade e boa posição em rankings; tais acontecimentos surgem como resultado e não como um motivador de suas práticas. Razões socioculturais à internacionalização também são citadas como missões das universidades, pois elas devem devolver à sociedade alunos com competência e capazes de atuarem no contexto global. Há também razões políticas, visando ao atendimento dos anseios da aldeia global, pois, ao estabelecer acordos internacionais, a universidade representa o país, é seu porta-voz e criadora de um ambiente cordial. Essas atividades são retroalimentadas através de trocas, sejam elas de conhecimento ou de intercâmbio de discentes e docentes, e exercem papel político ao darem identidade nacional, dentro do contexto internacional, para a manutenção da paz e aproximação dos povos.

A seguir, o quadro 1 apresenta certas razões e motivações, em níveis institucional e nacional, à internacionalização acadêmica.

Quadro 01 - Razões e Motivações Institucionais e Nacionais à Internacionalização Acadêmica

\begin{tabular}{|c|c|c|}
\hline RAZÕES & NÍVEL INSTITUCIONAL & NÍVEL NACIONAL \\
\hline Acadêmicas & $\begin{array}{l}\text { - Inclusão e promoção de práticas de } \\
\text { excelente ensino de nível } \\
\text { internacional;Inclusão à cultura e a } \\
\text { conhecimentos } \\
\text { internacionais;Aumento da } \\
\text { reputação e da visibilidade } \\
\text { internacionais;Inclusão e promoção } \\
\text { das condições de pesquisa e da } \\
\text { divulgação científica; } \\
\text { - Aperfeiçoamento de discentes, } \\
\text { docentes e corpo técnico- } \\
\text { administrativo. }\end{array}$ & $\begin{array}{l}\text { - Aperfeiçoamento de recursos } \\
\text { humanos adequados às demandas } \\
\text { internacionais; } \\
\text { - Acesso a resultados de pesquisas e } \\
\text { avanços técnico-científicos. }\end{array}$ \\
\hline Socioculturais & $\begin{array}{l}\text { - Formação de um ambiente } \\
\text { culturalmente diversificado; } \\
\text { - Inclusão a novas culturas e } \\
\text { ampliação de horizontes culturais. }\end{array}$ & $\begin{array}{l}\text { - Desenvolvimento sociocultural da } \\
\text { nação. }\end{array}$ \\
\hline Políticas & $\begin{array}{l}\text { - Criação de parcerias e convênios } \\
\text { para fins diversos; } \\
\text { • Visibilidade e reputação } \\
\text { internacionais. }\end{array}$ & $\begin{array}{l}\text { - Formação de alianças } \\
\text { estratégicas;Consolidação da } \\
\text { identidade nacional; } \\
\text { - Inserção do país no cenário } \\
\text { internacional de produção de } \\
\text { conhecimento. }\end{array}$ \\
\hline Econômicas & $\begin{array}{l}\text { - Aporte de recursos financeiros; } \\
\text { - Melhores avaliações pelos órgãos } \\
\text { de fomento. } \\
\text { - Competitividade internacional. }\end{array}$ & - Entrada de recursos do exterior. \\
\hline
\end{tabular}

Fonte: Adaptado de Rocha, 2016.

Inseridas nesse contexto de intensa globalização e no anseio em atender às demandas da sociedade, as IES estão sujeitas aos impactos da globalização. Assim, entende-se que a 
internacionalização do ensino superior é um motivo de adequação a essas demandas, mas há outros impactos decorrentes da globalização impostos a diferentes áreas da atividade humana. Ainda sobre a internacionalização, Miura (2006) apresenta o seguinte esclarecimento:

A partir da década de 1980, a internacionalização das IES ganha importância no cenário mundial, sobretudo, impulsionada pela clara percepção de que o desenvolvimento científico deve acontecer em âmbito internacional, livre das limitações impostas pelas fronteiras. Assim, se faz necessária também a diversificação dos modos de aprendizagem, tanto em tempo integral quanto parcial. Todas estas questões contribuíram direta ou indiretamente para que as atividades de internacionalização, nas últimas décadas, saíssem das margens e tornando-se tema central nas IES.

Em razão de ter-se tornado o quarto pilar da educação, e na busca de esclarecer as motivações para a internacionalização, pudemos observar as já citadas quatro principais categorias: sociocultural, política, acadêmica, econômica (KNIGHT; WIT, 1997), e, nesse sentido, Knight (2004) faz a seguinte distinção entre os motivos nos âmbitos nacional e institucional:

- Em nível nacional ou interno, seriam os seguintes motivos: Construir um perfil internacional seguro, lembrando que os rankings internacionais não são motivadores de internacionalização, mas são sinalizadores da reputação internacional de uma IES; Melhorar a qualidade, com cerne nos padrões internacionais; Formar profissionais com educação de elevados padrões de ensino; Gerar renda financeira, para a criação e manutenção de sistemas voltados ao incremento do ensino, da pesquisa e da extensão; Firmar parcerias estratégicas com outros centros de ensino e pesquisa, órgãos de fomento nacionais ou internacionais, organizações governamentais e iniciativa privada, que podem influenciar positivamente o alcance de seus objetivos institucionais e produzir conhecimento - atividade finalística das IES.

- As razões externas nacionais dizem respeito ao papel das IES no crescimento de uma nação, ao formarem capital humano capacitado ao seu incremento social e econômico; Internacionalização da IES como forma de crescimento da nação por meio do incremento de sua ciência e consequente acesso das IES a outras com padrão internacional e o entendimento mútuo das nações, abrindo fronteiras para que os indivíduos tenham trânsito nas diversas culturas.

- É observado que esforços internos ganham força, quando os externos atuam por meio de políticas públicas voltadas à internacionalização, seja por meio de verba, criação de programas e/ou de estímulos por parte das agências de fomento nacionais. Ao fazermos ligação desse empenho por parte das agências de fomento, vimos que a CAPES possui 
papel relevante quanto à internacionalização das IES, pois, pelo resultado decorrente da avaliação por ela realizada, é concedido reconhecimento da qualidade da pós-graduação stricto sensu brasileira e são realizadas concessões de bolsas e de recursos, destinados à pesquisa. Igualmente, a avaliação identifica as assimetrias regionais e de áreas estratégicas, com o objetivo de direcionar demandas de indução para a criação e expansão de PPG brasileiros.

Inferimos que a avaliação dos PPG é um instrumento de indução à internacionalização das IES, pois, quando seus PPG recebem notas de excelência, são disponibilizados mais recursos e, assim, com mais recursos, pode-se ampliar sua atuação, nacional e internacionalmente, dando-lhes mais projeção (CAPES, 2018). Consideramos que o processo de internacionalização das IES subsiste, independentemente de serem criadas políticas formais, uma vez que todos os PPG participantes do SNPG já assimilaram os critérios e as normas estabelecidos pela Agência e se esforçam em alcançar nota de excelência. Lembrando ainda que, mesmo que tenham alcançado essa excelência, devem manter a qualidade nos prérequisitos exigidos pelo SNPG, a fim de preservá-la.

E, com uma nova estratégia de internacionalização das IES, observa-se o esforço da Agência para a manutenção e ampliação desse processo de internacionalização das IES com o lançamento do referenciado Programa CAPES/PRINT, que flexibilizará a utilização dos novos recursos em diversas modalidades de concessões no exterior, a exemplos do Doutorado Sanduíche; Professor Visitante Sênior; Capacitação em cursos de curta duração (summer/winter schools); Auxílio para Missões de Trabalho no Exterior e Recursos para Manutenção de Projetos. No País, as concessões serão feitas nas modalidades de Professor Visitante no País, Jovem Talento com Experiência no Exterior e Pós-Doutorado com Experiência no Exterior.

Como já foi dito, a internacionalização é um meio, e não um fim em si mesmo, e ainda, conforme definição dada pelo presidente da Capes, Abílio Baeta, "O Print deve trazer uma transformação significativa das universidades baseado na convicção de que a internacionalização é um imperativo" (CAPES, 2018). Desse modo, a internacionalização das IES, por ser um processo imprescindível de incremento à educação superior e de desenvolvimento da pós-graduação brasileira, terá no PRINT um meio de torná-las responsivas aos atuais desafios impostos pelo mundo globalizado. 


\section{CONSIDERAÇÕES FINAIS}

O recorte realizado neste artigo procurou destacar o amadurecimento do SNPG e a assimilação do importante papel da internacionalização acadêmica das IES, a fim de demonstrar como esse processo fortalece e integra as relações das comunidades científicas internacionais, estreitando o vínculo de seus pesquisadores, além de dar-lhes inserção e visibilidades mundiais. Procurou-se demonstrar a importância da avaliação dos cursos de pós-graduação, realizada pela CAPES, como instrumento catalisador desse processo de internacionalização acadêmica, e da atual cooperação acadêmica desenvolvida pela agência, que encontra-se sedimentada, inexistindo assistencialismo em suas parcerias, de modo que seus acordos seguem diretrizes, objetivos e normas pré-estabelecidos à execução da cooperação. A agência também procura utilizar processos ágeis com normas claras, transparentes e pragmáticas, ao observar aspectos importantes na formulação de seus editais, tais como:

- Todos os PPG que integram o SNPG podem concorrer desde que cumpram as regras do edital;

- Não há delimitação de região geográfica ou de área de conhecimento, exceção a editais específicos que visem a uma região menos favorecida ou a uma área estratégica;

- As propostas devem estar apoiadas em interesses e/ou necessidades institucionais relevantes;

- Reciprocidade entre os cooperantes, na execução das atividades de pesquisa;

- Contribuição efetiva na qualificação de RH dos PPG; e

- Incremento à produção científica.

Por fim, pode ser observado que o movimento de internacionalização das IES brasileiras deu-se inicialmente por meio de concessões de bolsas de estudos no exterior, almejando a criação de massa crítica qualificada e capaz de suprir carências técnico-científicas brasileiras, e que, em seguida, ela estivesse preparada a fundamentar e a sustentar PPG stricto sensu no território brasileiro. Hoje, essa massa científica está sedimentada, fortalecida e reconhecida internacionalmente.

\section{REFERÊNCIAS}

ALTBACH, Philip G. Globalização e universidade: mitos e realidades em um mundo desigual. Washington, DC: Associação Nacional de Educação, 2004. p. 63-74.

ALTBACH, Philip G.; KNIGHT, Jane. The Internationalization of higher Education: Motivations and Realities. Journal of Studies in International Education, v. 11, n. 3-4, p. 290-305, 2007. 
ANTUNES, Fátima. Governação e Espaço Europeu de Educação: regulação da educação e visões para o projecto 'Europa'. Revista Crítica de Ciências Sociais, n. 75, p. 63-93, 2006. Disponível em: $<$ https://rccs.revues.org/901 >. Acesso em: 1 jun. 2017.

BAUMAN, Zygmunt. Globalização: as consequências humanas. Rio de Janeiro: Zahar, 1999.

BRASIL. Constituição (1988). Constituição da República Federativa do Brasil de 1988. Diário Oficial da República Federativa do Brasil, Brasília, DF, 5 out. 1988.

BRASIL. Lei n ${ }^{\circ}$ 9.394, de 20 de dezembro de 1996. Estabelece as diretrizes e bases da educação nacional. Diário Oficial da República Federativa do Brasil, Brasília, 23 dez. 1996.

CAPES. Antecedentes: os planos anteriores. In: . Ministério da Educação. Plano Nacional de Pós-graduação - PNPG 2011-2020. Brasília, DF: Capes, 2010. p. 16-38. v. 1.

CAPES. Ministério da Educação. Avaliação da CAPES aponta crescimento da pós-graduação brasileira. CAPES, Brasília, 19 set. 2017. Atualizado em: 20 set. 2017. Disponível em: $<$ http://www.capes.gov.br/sala-de-imprensa/noticias/8558-avaliacao-da-capes-apontacrescimento-da-pos-graduacao-brasileira>. Acesso em: 18 jan. 2018.

CAPES. Ministério da Educação. Debate aborda financiamento privado para ciência brasileira. CAPES, Brasília, 2 fev. 2018. Disponível em: $<\underline{\text { http://www.capes.gov.br/sala-de- }}$ imprensa/noticias/8740-debate-aborda-financiamento-privado-para-ciencia-brasileira $>$. Acesso em: 18 jan. 2018.

DIAS SOBRINHO, José. Educação superior, globalização e democratização: qual universidade? Revista Brasileira de Educação, Rio de Janeiro, n. 28, p. 164-173, 2005.

GOERGEN, Pedro. A internacionalização dos programas de pós-graduação. Revista Espaço Pedagógico, Passo Fundo, v. 19, n. 2, Passo Fundo, 2013.

IANNI, O. Teorias da Globalização. 9. ed. Rio de Janeiro: Civilização Brasileira, 2002.

KNIGHT, Jane. Comparative, International, and Development Education Centre, Ontario Institute for Studies in Education, University of Toronto, Journal of Studies in International Education, Toronto, v. 8, n. 1, p. 5-31, 1 mar. 2004. Disponível em: <http://journals.sagepub.com/doi/10.1177/1028315303260832>. Acesso em: 1 ago. 2017.

KNIGHT, Jane; WIT, Hans de. "Internacionalização do Ensino Superior nos Países da ÁsiaPacífico”. European Association for International Education/EAIE, Amsterdã, 1997.

LOMBAS, M. L. de S. A mobilidade internacional de pós-graduandos e pesquisadores e a internacionalização da produção do conhecimento: efeitos de uma política pública no Brasil. 2013. 204 f. Tese (Doutorado em Sociologia) -Universidade de Brasília, Programa de Pós-Graduação em Sociologia, Brasília, DF, 2013.

MENDES, Durmeval Trigueiro. O planejamento educacional no Brasil. Rio de Janeiro: Editora da Universidade do Estado do Rio de Janeiro, 2000. 
MIURA, Irene Kazumi. O processo de internacionalização da Universidade de São Paulo: um estudo de três áreas de conhecimento. 2006. 365f. Tese (Livre Docência)-Universidade de São Paulo, Faculdade de Administração, Economia e Contabilidade, Ribeirão Preto, 2006.

NOBRE, Lorena Neves; FREITAS, Rodrigo Randow. A Evolução da Pós-Graduação no Brasil: histórico, políticas e avaliação. Brazilian Journal of Production Engineering-BJPE, v. 3, n. 2, p. 26-39, 2017.

ROCHA, Mateus de Souza. Proposta de Balanced Scorecard para auxílio ao processo de gestão estratégica da internacionalização do ensino superior: um estudo de caso em universidades públicas. 2016. Tese (Doutorado em Administração de Organizações) Universidade de São Paulo, Faculdade de Administração, Economia e Contabilidade, Ribeirão Preto, SP, 2016.

VEIGA, Maria Amélia Pina Tomás. Oportunidades e ameaças de Bolonha (um processo em curso) e a universidade europeia (um projecto em discurso) num contexto de globalização. 2003. Dissertação (Mestrado em Psicologia e Educação) - Universidade do Porto, Portugal, 2003.

Recebido em: 15 de outubro de 2018.

Aprovado em: 5 de dezembro de 2018. 